\title{
ЭПИДЕМИОЛОГИЧЕСКИЙ ПРОФИЛЬ ТЯЖЕЛОЙ МАЛЯРИИ У НОВОРОЖДЕННЫХ И ПОДРОСТКОВ, ПРОЛЕХАВ В СОПРОВОЖДЕНИИ 2016 ГОДУ В СПРАВОЧНОЙ БОЛЬНИЦЕ В ШТАTE AMАРÁ, БРАЗИЛИЯ
}

\section{ОРИГИНАЛЬНАЯ СТАТЬЯ}

BRITO, Maysa Vasconcelos de ${ }^{1}$, FRANÇA, Ana Maria Braga da Silva², FECURY, Amanda Alves ${ }^{3}$, OLIVEIRA, Euzébio de ${ }^{4}$, DENDASCK, Carla Viana ${ }^{5}$, DIAS, Cláudio Alberto Gellis de Mattos ${ }^{6}$

BRITO, Maysa Vasconcelos de. Et al. Эпидемиологический профиль тяжелой малярии у новорожденных и подростков, пролехав в сопровождении 2016 году в справочной больнице в штате Аmapá, Бразилия. Revista Científica Multidisciplinar Núcleo do Conhecimento. Год 05, эд. 06, Vol. 12, стр. 05-23. Июнь 2020 года. ISSN: 2448-0959, Ссылка доступа: https://www.nucleodoconhecimento.com.br/здравоохранение/тяжелой-малярии, DOI: $10.32749 /$ nucleodoconhecimento.com.br/ru/87556

\footnotetext{
${ }^{1}$ Биомедицинская, phD в актуальных заболеваний, профессор и исследователь в Estácio в Sá колледж, Macapá.

${ }^{2}$ Биомедицинская, Техника Детской и Подростковой Больницы (Масара́ - Amapá).

${ }^{3}$ Биомедицин, доктор философии по тропическим болезням, профессор и исследователь на курсе медицины в кампусе Масара́ и в программе последипломного образования в области медицинских наук (PPGCS) Федерального университета Amapá (UNIFAP).

${ }^{4}$ Биолог, доктор тропических болезней, профессор и исследователь курса физического воспитания Федерального университета Pará (UFPA).

${ }^{5}$ Богослов, кандидат клинических психоанализов. В течение 15 лет он работал с научной методологией (методом исследования) в научно-производственной ориентации магистрантов и докторантов. Специалист по маркетинговым исследованиям и исследованиям в области здравоохранения.

${ }^{6}$ Биолог, кандидат теоретических и летных исследований, профессор и исследователь Высшей программы профессионального и технологического образования (PROFEPT) Института базового, технического и технологического образования Amapá (IFAP).
}

RC: 87556

Доступно в: https://www.nucleodoconhecimento.com.br/здравоохранение/тяжелой- 


\section{СВОДКА}

В настоящем исследовании учитывались не только инфекции Plasmodium falciparum, которые обычно рекомендуются в качестве основной причины тяжелой малярии, но и были тщательно описаны осложнения, связанные с Plasmodium vivax. Цель этой статьи заключалась в выявлении эпидемиологического, клинического и лабораторного профиля тяжелой малярии у пациентов, лечения которых лечилось в Детской и Подростковой больнице в Macapá - Amapá. Было проведено эпидемиологическое, описательное исследование ретроспективного характера. Данные были получены путем консультаций в медицинских записях пациентов за 2016 год. Тяжелой малярией было рассмотрено 47 случаев. Преобладали пациенты мужского пола - 63,8\%, в возрасте до 5 лет - 59,6\% случаев. Что касается вида, наиболее частыми были заражения $P$. vivax (72\%) по сравнению с $P$. falciparum (28\%). Месяцами с наибольшим количеством госпитализаций были сентябрь и ноябрь, оба - по 17\%. Основные клинические проявления: лихорадка, бледность и кашель. Наиболее часто встречающиеся состояния, указывающие на серьезность: рвота $87 \%$, желтуха 23\%, одышка и возраст <1 год, оба - 21\%. Гематологические исследования показали, что у 91\% пациентов уровень эритроцитов ниже контрольных значений, а в 100\% случаев - низкий уровень гемоглобина и гематокрита; тромбоцитопения была выявлена в $72 \%$ случаев. Измененные результаты наиболее клинически важных биохимических доз были: мочевина, трансаминазы, глицимеа и С-реактивный белок. Выявление эпидемиологических, клинических и лабораторных данных о тяжелой фрорме малярии способствует ранней диагностике и адекватному лечению заболевания.

Ключевые слова: Тяжелая малярия, Plasmodium vivax, эпидемиология.

RC: 87556

Доступно в: https://www.nucleodoconhecimento.com.br/здравоохранение/тяжелой- 


\section{ЗНАКОМСТВО}

Малярия является важной проблемой общественного здравоохранения, представляющих большой глобальный интерес. Это инфекционное заболевание, вызванное простейшим родом Plasmodium, передаваемым при укусе самки комара рода Anopheles зараженный. Основными видами, связанными с малярией человека, являются Plasmodium falciparum, P. vivax, P.malarie e P. ovale. В последнее время сообщалось о некоторых случаях малярии в результате заражения $P$. knowlesi и $P$. cynomolgi, который, как известно, вызывает малярию у обезьян (TA et al., 2014; RAMASSAMI, 2014). Наиболее распространенными и подтвержденными в Бразилии являются: P.vivax, P. falciparum e P. malarie, поскольку $P$. ovale чаще встречается в регионах Африки (BRASIL, 2009).

Развитие переносчиков малярии вполне осуществимо в легальной Амазонки. Штат Amapá является штатом северного региона, компонентом правовой Амазонки и одним из государств с более благоприятными условиями для деторождения переносчика и передачи малярии. Что касается Бразилии, то государство Атара́ входит в число районов со средним и высоким риском заражения (SANTOS; SANTOS, 2011).

Возникновение случаев заболевания малярией связано с рядом фракторов, включая деятельность по извлечению природных ресурсов, способных потенцировать передачу болезни. В этом смысле Аmара́ представляет себя как регион, в экономике и выживании которого используется природные ресурсы (MACIEL; OLIVEIRA, 2014). Учитывая благоприятную окружающую среду и потребности населения в использовании природных ресурсов, уровень заболеваемости малярией в Атара́ высок, а случаи с более высокой заболеваемостью вызваны P. vivax, (90\% случаев) (SANTOS; SANTOS, 2011).

RC: 87556

Доступно в: https://www.nucleodoconhecimento.com.br/здравоохранение/тяжелой- 
Фактические данные свидетельствуют о том, что клинический спектр малярии зависит от интенсивности передачи, вида паразитов и иммунного статуса пациента. Таким образом, клиническое представление малярии, как представляется, различаются между детьми и взрослыми (WASSMER et al., 2015).

\section{ЦЕЛЬ}

Определить эпидемиологический, клинический и лабораторный профиль тяжелой малярии у новорожденных и подростков, пролехав в 2016 году в рефреральной больнице в штате Amapá, Бразилия.

\section{МЕТОД}

Это ретроспективное описательное эпидемиологическое исследование, проведенное в Детской и подростковой больнице (НСA), расположенной в городе Масара́ в штате Amapá на севере Бразилии. Данные для этого исследования были получены путем обращения к базе данных Службы медицинских архивов (SAME) HCA. Для записи собранной информации из базы данных были взяты следующие темы: демографические переменные (пол, возраст, происхождение ...), клинические переменные: количество госпитализаций, продолжительность пребывания, инфекционные виды ( $P$. vivax, P. falciparum, P. malarie), клинические проявления (лихорадка, миалгия, озноб, олигурия, желтуха, гиперпирексия (выше $\left.41^{\circ} \mathrm{C}\right)$, судороги и т. д.) и результаты лабораторных анализов (анализ крови, гемоскопия (толстая капля) и биохимические измерения (мочевина, креатинин, аспартатаминотрансфераза (AST) и аланинаминотрансфераза (ALT), PCR (C-реактивный белок) и глюкоза крови).

Дети и подростки обоих полов (в возрасте от 29 дней от рождения до 15 лет) лечатся с 1 января по 31 декабря 2016 года лабораторным подтверждением

RC: 87556

Доступно в: https://www.nucleodoconhecimento.com.br/здравоохранение/тяжелой- 
малярии (исследования плазмодия с положительными результатами) и представили клинические и лабораторные проявления тяжелой малярии в соответствии с описанным в Guia Prático de Malária 2010 года, были включены., который имеет условия, указывающие на тяжесть заболевания и необходимость госпитализации: иммунодепрессированные пациенты, пациенты с любым из признаков опасности для тяжелой малярии: (гиперпирексия больше, чем $41^{\circ} \mathrm{C}$, судороги, гиперпаразитемия (>200000/mm $\left.{ }^{3}\right)$, повторная рвота олигурия, диспинея, интенсивная анемия, желтуха, кровотечение и артериальная гипоция.

Исследовательский проект был представлен и одобрен Комитетом по этике и исследованиям колледжа Эстесио де Macapá в соответствии с этическими стандартами, установленными в резолюции Национального совета здравоохранения № 466 от 12 декабря 2012 года, которая касается исследований с участием людей (BRASIL, 2013).

\section{РЕЗУЛЬТАТЫ И ОБСУЖДЕНИЕ}

Amazônia, регион, где расположено государство Amapá, способствует формированию эпидемиологической связи передачи малярии в связи с ее географическими, климатическими и социально-культурными аспектами. Таким образом, большое значение имеет знание динамики заболевания с точки зрения особенностей каждого эндемического региона и возрастной группы развития населения. (BRASIL, 2016).

Первоначально эпидемиологические аспекты пациентов, обуковив их, характеризовались полом, возрастной группой, происхождением и инфекционными видами. Так, преобладают пациенты мужского пола, которые составили 63,8\% (n=30) случаев заболевания, в то время как только $36,2 \%$ $(n=17)$ принадлежали женщинам (рисунок 1).

$\mathrm{RC}: 87556$

Доступно в: https://www.nucleodoconhecimento.com.br/здравоохранение/тяжелой- 
Рисунок 1 - Процент случаев тяжелой малярии в 2016 году в штате Amapá, по признаку пола.

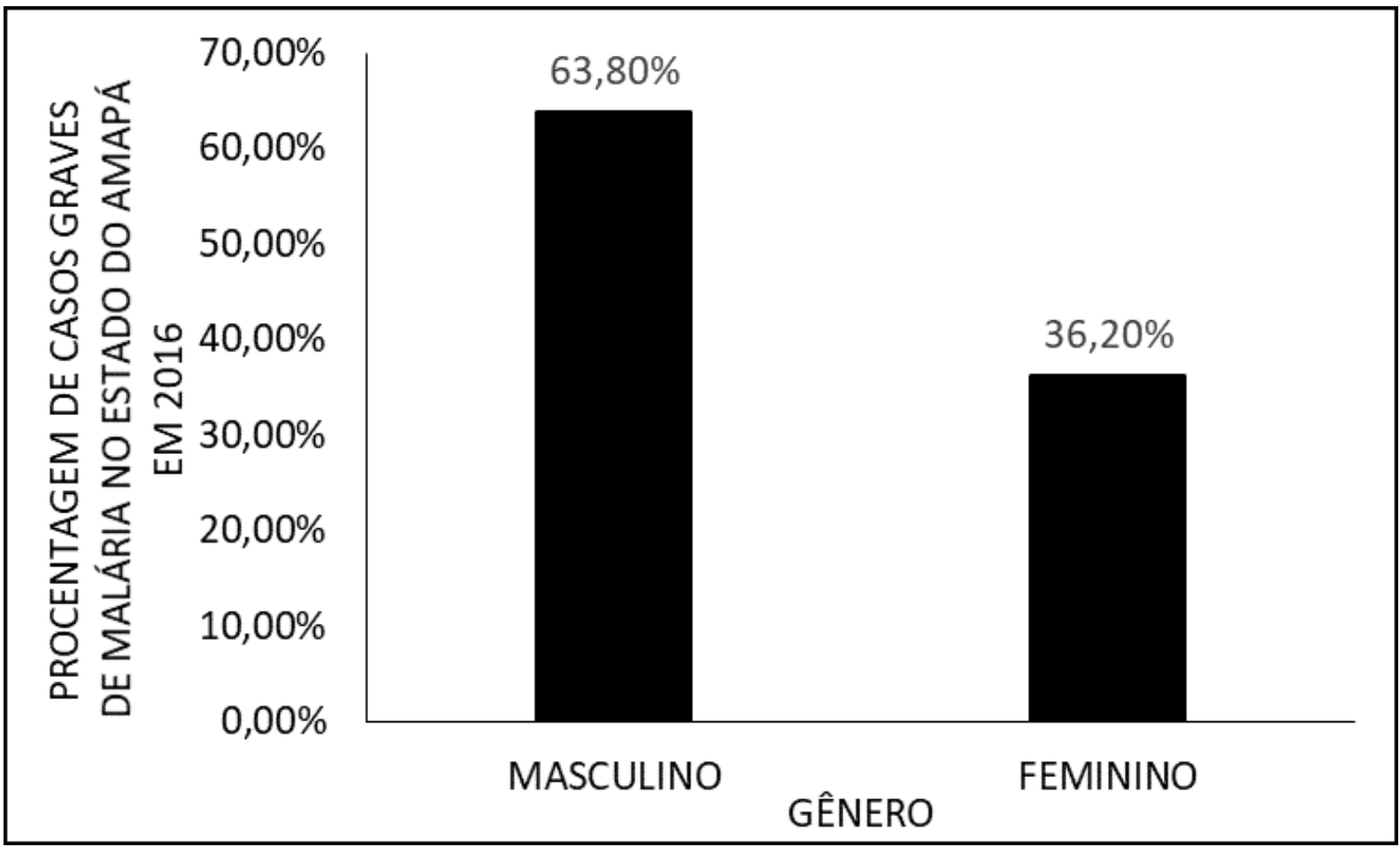

По словам Monteiro, Ribeiro и Fernandes (2013), лица обоих полов рискуют за заразились малярией. Мужчины, как правило, менее осторожны со здоровьем, чем женщины. Работа в районах, подверженных присутствию переносчиков, также обычно занята мужчинами (ALMEIDA et al., 2020).

Более половины 28 (59,6\%) случаев заболевания имели место у пациентов, принадлежащих к возрастным группам до 5 лет; от 6 до 10 лет, при этом 29,8\% $(n=14)$ случаев заболевания. Только $10,6 \% \quad(n=5)$ случаев произошло у пациентов в возрасте от 11 до 15 лет (рисунок 2).

RC: 87556

Доступно в: https://www.nucleodoconhecimento.com.br/здравоохранение/тяжелой- 
Рисунок 2 - Процент случаев тяжелой малярии в 2016 году в штате Amapá, по возрастным группам.

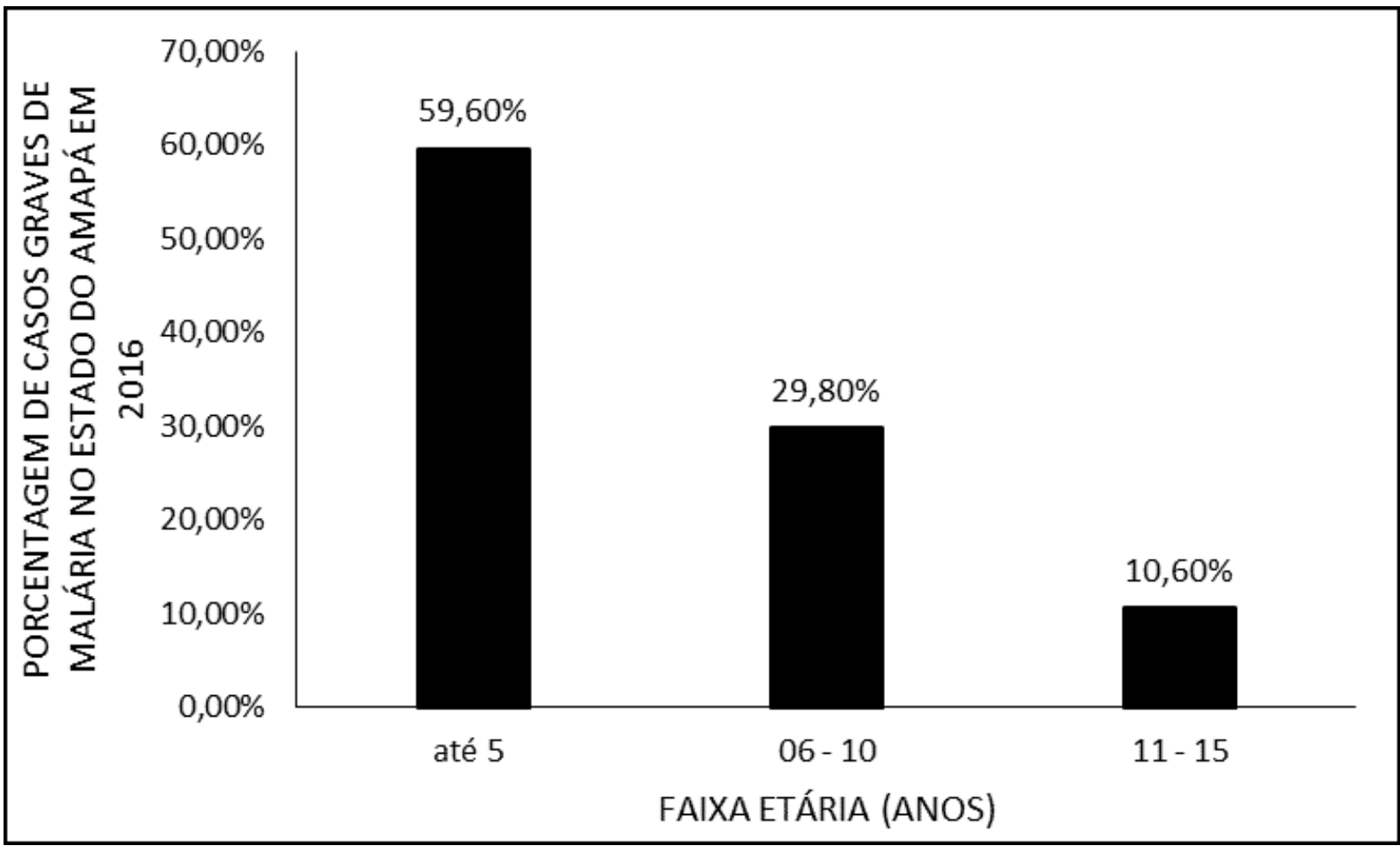

Что касается возрастной группы до 5 лет, в которой число случаев заболевания было выше, это может быть связано с восприимчивостью ребенка к приобретению заболеваний, а также потому, что они являются частью группы риска и тот фракт, что в данном исследовании первая инфекция преобладает 94\% случаев, что является фрактором, который способствует тяжести, поскольку человек не представляет какой-либо специфический иммунитет против плазмодия (VENTURA et al., 1999; GOMES et al., 2011; RIBEIRO, 2012).

Что касается заражающих видов, то в данном исследовании не было никаких записей о наличии P. malarie и смешанная малярия, чаще всего плазмодийные Plasmodium vivax с $72 \%$ (n No 34) по отношению к $P$. falciparum с участием $28 \%$ (n'13) зарегистрированных случаев (рисунок 3).

RC: 87556

Доступно в: https://www.nucleodoconhecimento.com.br/здравоохранение/тяжелой- 
Рисунок 3 - Процент случаев тяжелой малярии в 2016 году в штате Amapá, по возрастным группам.

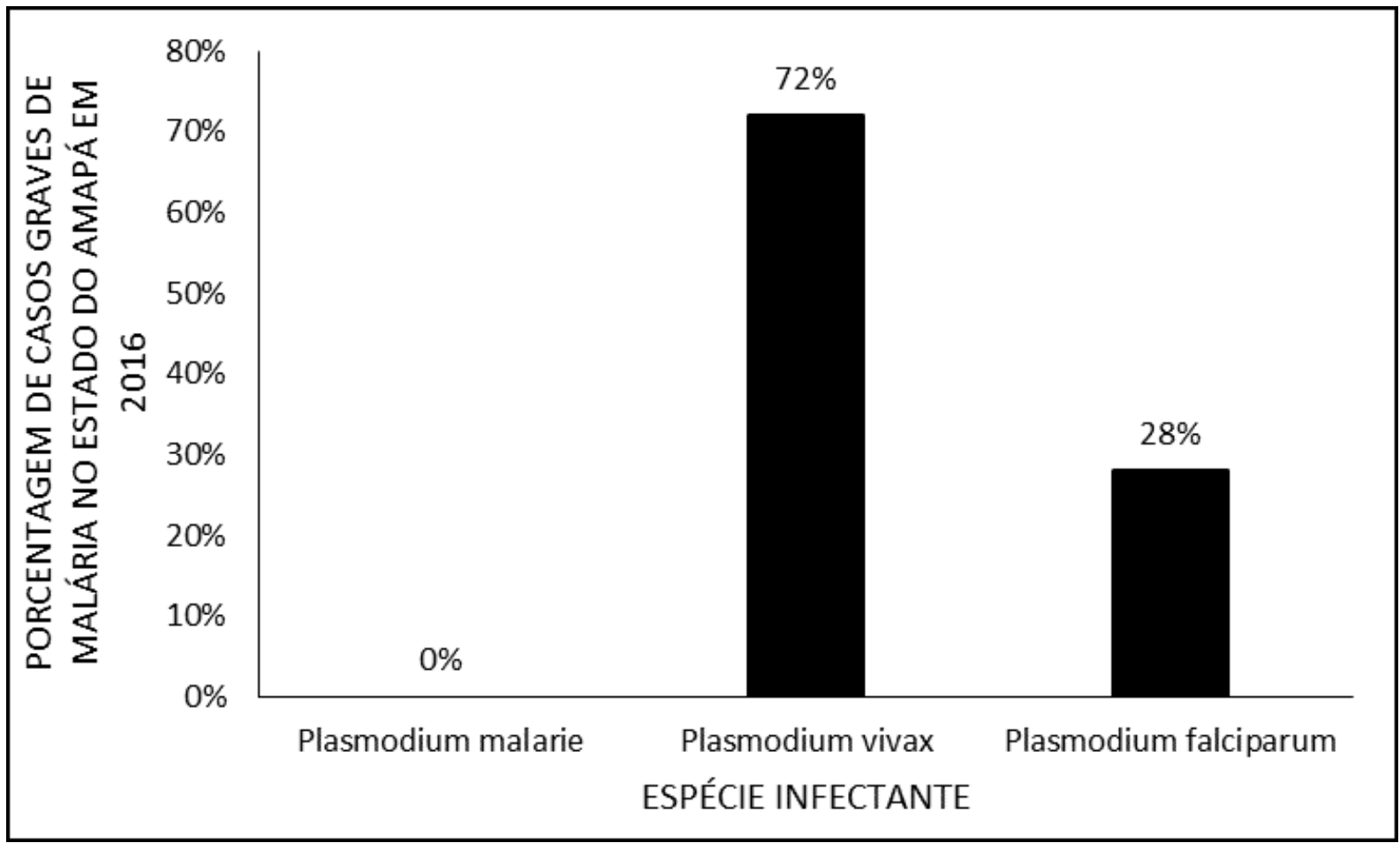

Этот вывод подтверждает, что обнаружили Santos и Santos (2011), которые в своем исследовании показывают более высокую заболеваемость $P$. vivaxв штате Amapá. C другой стороны, при анализе аспекта тяжести это количество $P$. vivax не так часто, поскольку большинство обследований показывают тяжелую малярию, связанную с P. falciparum (KIRCHGATTER; PORTILLO, 2005; GOMES, 2011; MIOTO; GALHARDI; AMARANTE, 2012; PARISE, 2009).

Происхождение этих пациентов в соответствии с таблицей 1 показывает, что среди муниципалитетов Атара́, Масара́ выделялся 29 случаев, 79\% (n-23) P. vivax и $21 \%$ (6) P. falciparum. Так как это можно отнести к тому, что работы велись в столице.

RC: 87556

Доступно в: https://www.nucleodoconhecimento.com.br/здравоохранение/тяжелой- 
Таблица 1 - Распределение пациентов, госпитализированных в НСА с тяжелой малярией в соответствии с муниципалитетом проживания и инфекционных видов в 2016 году, Масара́-АР.

\begin{tabular}{|c|c|c|c|c|c|c|}
\hline \multirow{2}{*}{ Município de procedência/ Espécie infectante } & \multicolumn{2}{|c|}{ P. vivax } & \multicolumn{2}{|c|}{ P. falciparum } & \multicolumn{2}{|c|}{ Total } \\
\hline & $\mathrm{N}$ & $\%$ & $\mathrm{~N}$ & $\%$ & $\mathrm{~N}$ & $\%$ \\
\hline Macapá & 23 & 79 & 6 & 21 & 29 & 100 \\
\hline Mazagão & 2 & 67 & 1 & 33 & 3 & 100 \\
\hline Ferreira Gomes & 1 & 25 & 3 & 75 & 4 & 100 \\
\hline Porto Grande & 1 & 33 & 2 & 67 & 3 & 100 \\
\hline Tartarugalzinho & 4 & 100 & 0 & 0 & 4 & 100 \\
\hline Oiapoque & 1 & 100 & 0 & 0 & 1 & 100 \\
\hline Outros Estados (PA) & 2 & 67 & 1 & 33 & 3 & 100 \\
\hline Total & 34 & 72 & 13 & 28 & 47 & 100 \\
\hline
\end{tabular}

Fonte: Same/HCA

Аналогичный случай наблюдался в исследовании, разработанном в справочной больнице в Belém do Pará, в котором только другие муниципалитеты были также непредставительными (MONTEIRO; RIBEIRO; FERNANDES, 2013). Таким образом, хотя весь штат Аmapá является эндемическим районом, предполагается, что населению оказывается помощь при надлежащей диагностике и лечении в отделениях более низкой сложности в муниципалитетах проживания.

По-прежнему в таблице 1 распределение видов по муниципалитетам отличается от других представленных: Ferreira Gomes c 75\% (3/4) и Porto Grande 67\% (2/3) заражения $P$. falciparum, именно здесь это подтверждается. незначительное преобладание случаев заражения этим видом, общий результат нескольких исследований, в которых преобладали случаи тяжелой малярии, вызванной P. falciparum (KIRCHGATTER; PORTILLO, 2005; PARISE, 2009; GOMES, 2011; MIOTO; GALHARDI; AMARANTE, 2012).

Муниципалитет Amapawith самое низкое число случаев было Оiapoque с только 1 причиненным P. vivax. Остальные 3 случая были зарегистрированы у $\mathrm{RC}: 87556$

Доступно в: https://www.nucleodoconhecimento.com.br/здравоохранение/тяжелой- 
пациентов из другого штата, в данном случае Pará из городов Breves и Afuá, $67 \%$ (n'2) P. vivax e 33\% (1) P. falciparum.

Месяцы с самой высокой частотой госпитализаций в связи с тяжелой малярией были сентябрем и ноябрем с 8 (17\%) госпитализации каждого. В то время как в марте, апреле и мае были те, с самым низким числом только 2\% (1) госпитализации, как показано в (рисунок 4). Сезонность малярии в каждом штате amazônica является переменной, но в целом в переходный период между сухим и влажным сезонами (BRASIL, 2016) приходится пик заболеваемости.

Рисунок 4 - Процент случаев тяжелой малярии в 2016 году в штате Amapá, в течение нескольких месяцев в году.

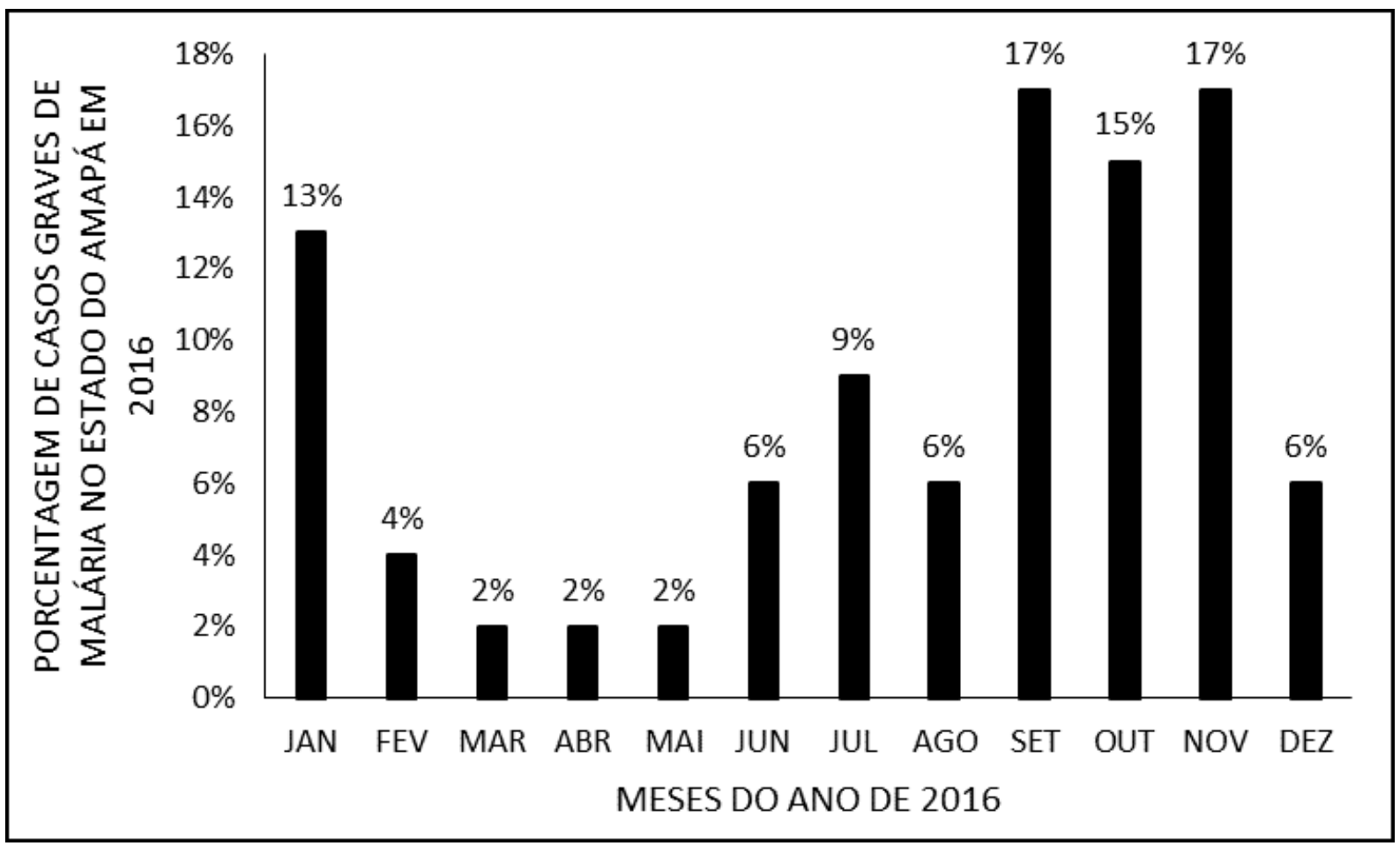

Основной переносчик малярии в Бразилии, Anopheles darlingi, размножается в больших количествах в низкотекутных, глубоких и затененных водах, и его

RC: 87556

Доступно в: https://www.nucleodoconhecimento.com.br/здравоохранение/тяжелой- 
размножение уменьшается в дождливые периоды (MONTEIRO; RIBEIRO; FERNANDES, 2013). В штате Amapá сентябрь представляет собой низкий индекс осадков, а в ноябре - начало сезона дождей, что может оправдать увеличение числа госпитализаций в связи с тяжелой малярией в данном исследовании. Безусловно, помимо изменения климата, с более высокой или меньшей заболеваемостью заболеванием могут быть связаны и другие фракторы, такие, как социально-экологические и, главным образом, различия в качестве и количестве контрольных мер (BRASIL, 2016).

Что касается продолжительности пребывания, то несколько фракторов могут повлиять на пребывание этих пациентов в больничной среде (рисунок 5) показывает, что большинство пациентов оставались в госпитализации до 5 дней. У двух пациентов, инфицированных $P$. vivax, которые оставались в течение 16-20 дней, у обоих были обезвоживание, анемия и тромбоцитопения, у одного из которых было больше, лейкопения, желтуха, колурия и очень высокие результаты теста на трансаминазы.

RC: 87556

Доступно в: https://www.nucleodoconhecimento.com.br/здравоохранение/тяжелой- 
Рисунок 5 - Процент случаев тяжелой малярии в 2016 году в штате Amapá, в течение нескольких дней госпитализации.

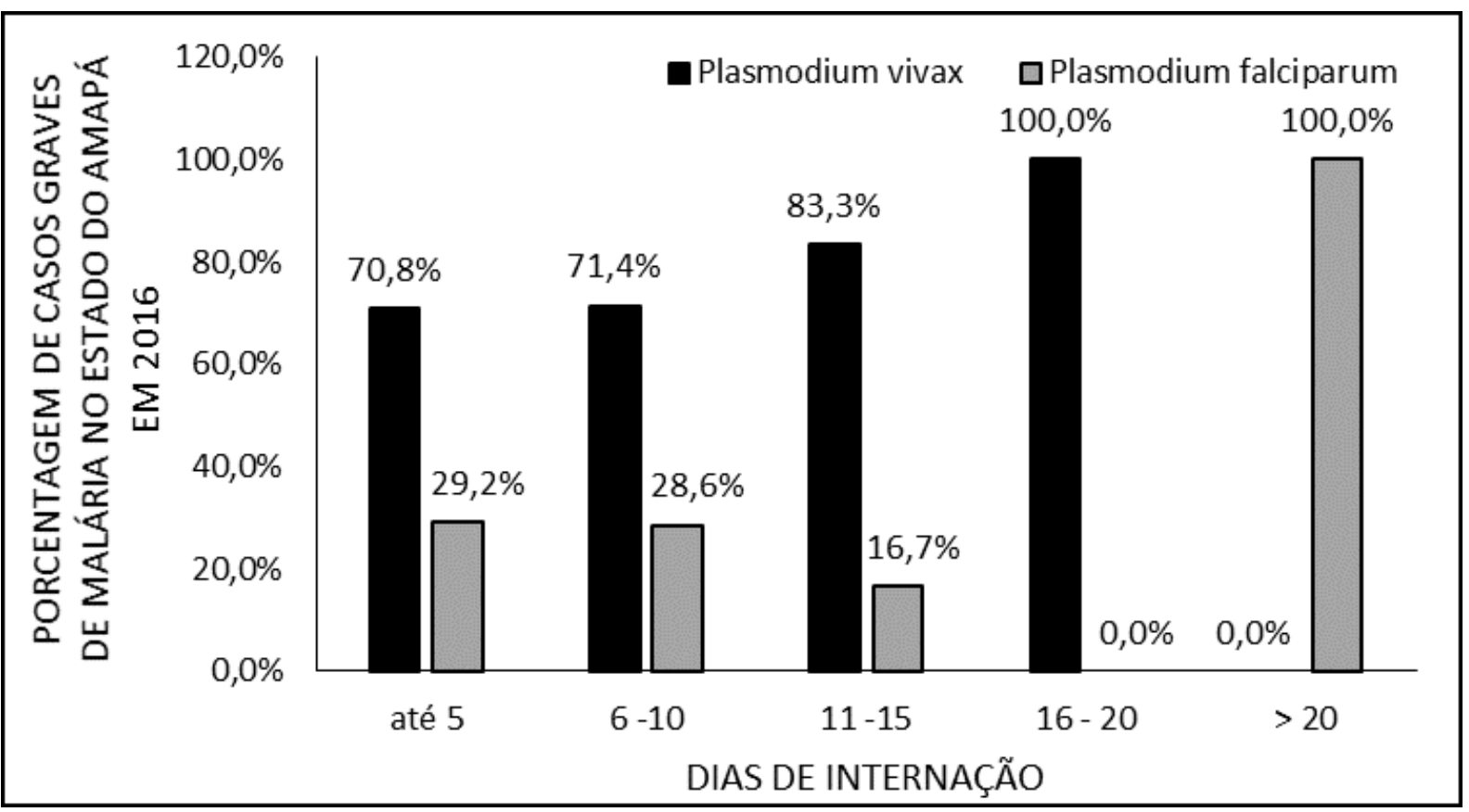

Пациенту с более чем 20-дневным заражением $P$. falciparum был один год, он имел высокую паразитемию 192000f / мм $^{3}$, гепатоспленоглию, тромбоцитопению, тяжелую анемию и перенес переливание эритроцитов. Хорошо задокументировано, что тяжелая анемия, клиническое проявление, присутствующее при тяжелой малярии, является важным фрактором, способствующим заболеваемости, продолжительности пребывания в больнице и даже смертности, возникающим при инфекциях $P$. falciparum, а довольно часто также и при P.vivax (PRICE et al., 2007; Naing et al., 2014).

Согласно проанализированной информации, время, прошедшее до диагноза малярии, которая также является решающим фрактором для лечения или эволюции к тяжести, были: до 3 дней 40\%, от 4 до 5 дней 38\% пациентов, от 6 до 10 дней 17\% и от 11 до 15 дней 4\% случаев. Все пациенты были выписаны только после улучшения клинического и лабораторного персонала, с

RC: 87556

Доступно в: https://www.nucleodoconhecimento.com.br/здравоохранение/тяжелой- 
направлением на амбулаторное наблюдение с детской инфекцией, не было никаких записей о смерти в изученный период.

Наиболее часто встречается клинические проявления: лихорадка, бледность, кашель, вздутие живота, боли в животе, обезвоживание, головная боль, холод и диарея (таблица 2). Лихорадка присутствовала в 100\% случаев, что для Ramos (2006), является основной причиной, которая приводит большинство пациентов обратиться за медицинской помощью и для выполнения дополнительных диагностических тестов.

Паллор, в свою очередь, произошел у 96\% пациентов, так как это очень частое клиническое проявление в случаях малярии, результат похож на результат Ventura et al. (1999 год), что в своем исследовании также проводится с детьми и подростками (85\%) представлены бледность.

Озноб и головная боль наблюдались только у 30\% (14/47) пациентов. Это симптомы, которые чаще всего сопровождают лихорадку, образуя классическую триаду малярии (BRASIL, 2009). Возможно, это не наблюдалось либо из-за отсутствия записей на момент анамнеза, либо из-за того, что это исследование с тяжелыми случаями, когда проявления могут проявляться нетипично.

Боль в животе присутствовала в (32\%) и диарея (23\%) пациентов, по словам Ramos (2006), может иметь малярийное происхождение, но в эндемичных районах социально-экономические условия, как правило, неустойчивы, с неадекватной санитарией, которая может привести к инфекциям кишечными паразитами при приеме пищи и загрязненной воды, которые могут сложить и усилить эти симптомы во время инфекции.

Пациенты с асцитом, холурией, сонливостью и диареей были инфицированы $P$. vivax. С другой стороны, пациенты со спленомегалией, анорексией и

$\mathrm{RC}: 87556$

Доступно в: https://www.nucleodoconhecimento.com.br/здравоохранение/тяжелой- 
тахикардией имели инфекцию $P$. falciparum, другие проявления в таблице 2 имели место как при инфекциях $P$. falciparum, так и $P$. vivax.

Таблица 2 - Распределение клинических проявлений, присутствующих у пациентов, госпитализированных в НСA с тяжелой малярией в 2016 году. Macapá, Amapá.

\begin{tabular}{|c|c|c|}
\hline \multirow{2}{*}{ Manifestações Clínicas } & \multicolumn{2}{|c|}{ Frequencia $(\mathrm{N}=47)$} \\
\hline & $\mathrm{N}$ & $\%$ \\
\hline Febre & 47 & 100 \\
\hline Palidez & 45 & 96 \\
\hline Tosse & 20 & 43 \\
\hline Distensão Abdominal & 20 & 43 \\
\hline Dor Abdominal & 15 & 32 \\
\hline Desidratação & 14 & 30 \\
\hline Calafrio & 14 & 30 \\
\hline Cefaléia & 14 & 30 \\
\hline Diarreia & 11 & 23 \\
\hline Edema & 6 & 13 \\
\hline Náuseas & 6 & 13 \\
\hline Hepatomegalia & 5 & 11 \\
\hline Hematúria & 4 & 9 \\
\hline Colúria & 3 & 6 \\
\hline Ascite & 2 & 4 \\
\hline Sonolência & 2 & 4 \\
\hline Esplenomegalia & 1 & 2 \\
\hline Anorexia & 1 & 2 \\
\hline Taquicardia & 1 & 2 \\
\hline
\end{tabular}

Fonte: Same/HCA

В последнее время подчеркивается наличие тяжелых случаев малярии, вызванной P. vivax (SIROMA, 2016; WASSMER et al., 2015; LACERDA et al., 2012). Многие из более серьезных клинических проявлений, которые возникают при малярии, вызванной $P$. falciparum, также были описаны у пациентов с $P$. vivax (MONTEIRO; RIBEIRO; FERNANDES, 2013; SALAS et al., 2013). Как показано в настоящем исследовании (таблица 3), у пациентов с диагнозом «малярия P. vivax» наблюдались рвота, желтуха, одышка, сильная анемия,

RC: 87556

Доступно в: https://www.nucleodoconhecimento.com.br/здравоохранение/тяжелой- 
олигурия, судороги и кровотечения. Это состояния, указывающие на серьезность и необходимость госпитализации (BRASIL, 2010).

Наиболее частым серьезным заболеванием была рвота, 100\% у пациентов, инфрицированных $P$. falciparum, и 68\% у пациентов, инфрицированных $P$. vivax, ситуация, которая в медицинских записях оправдывала значительную часть госпитализаций из-за того, что дети не переносила пероральные препараты, поэтому нуждалась в внутривенном введении. Согласно Ramos (2006), рвота может препятствовать правильному лечению, приводя к отказу от приема лекарств или их недостаточному всасыванию, а также к обезвоживанию, как показано в (Таблица 2), где 30\% (14/47) показали обезвоживание.

Респираторные признаки и симптомы, такие как кашель (Таблица 2) и одышка (Таблица 3), были зарегистрированы как у пациентов, инфицированных $P$. falciparum, так и P. vivax, но нельзя сказать, что они были вызваны исключительно малярией, поскольку результатов не было. проанализировали газометрию, спирометрию и рентгенологические исследования большинства, только последнее у пациента, у которого была диагностирована малярия, связанная с пневмонией.

Были изучены респираторные признаки и симптомы, а также легочные осложнения. Val et al. (2017) показали, что респираторные осложнения в значительной степени связаны со случаями смерти пациентов с тяжелой малярией. Carvalho et al. (2010) сообщили, что P. vivax обладает способностью прикрепляться к эндотелиальным клеткам легких человека. Для Salas et al. (2013) фризиопатогенные процессы могут быть общими для этих двух видов, например, секвестрация инфицированных эритроцитов из периферического кровообращения внутрь жизненно важных органов (легкие, мозг и почки) и цитоадгезия к эндотелиальной стенке капилляров этих органов.

RC: 87556

Доступно в: https://www.nucleodoconhecimento.com.br/здравоохранение/тяжелой- 
Согласно Carvalho et al. (2010), эти наблюдения приводят к модификации существующих парадигм патогенеза малярии и открывают путь для исследования патофизиологии инфекций $P$. vivax, поскольку эритроциты, инфицированные P. vivax, не имеют структур пуговиц (модификации поверхности) и потому что все формы паразита могут наблюдаться в периферической крови пациентов, стало догмой, что $P$. vivax не обладает способностью к секвестированию и, следовательно, к цитоадгезии (LOPES et al., 2014).

Другим обнаруженным серьезным заболеванием была тяжелая анемия в (5/47) случаях, в 4 случаях инфекция была вызвана $P$. vivax, a в 1 - $P$. falciparum. Тяжелая анемия, которая определяется как гематокрит менее $15 \%$ и гемоглобин менее 5 г / дл, обычно присутствует при тяжелой малярии из-за интенсивного разрушения и секвестрации эритроцитов, изменений эритропоэза и случайных кровотечений (BRASIL, 2010; GOMES et al., 2011; SIROMA, 2016).

В настоящем исследовании, девять пациентов, которые прошли переливание крови требуется концентрат красных кровяных клеток, и 2 из 9 также требуется тромбоцитов, из этих 9 пациентов восемь были инфицированы $P$. vivax, и только один на $P$. falciparum. Пациент с кровоизлиянием был одним из пациентов, перенесший переливание крови концентрата красных кровяных телец и тромбоцитов.

Аналогичные осложнения связаны с тяжелыми мларами с участием. P. vivax были описаны в других исследованиях, таких как тяжелая анемия, дисфункция печени, желтуха, тромбоцитопения с или без кровотечения (WASSMER et al., 2015; LACERDA et al., 2012; SALAS et al., 2013; )

Что касается возраста <1 года, в котором было (10/47) пациентов (таблица 3), то для Gomes et al (2011) тяжесть малярии зависит от взаимосвязи между хозяином (уязвимость и иммунный статус) и Plasmodium spp (виды

RC: 87556

Доступно в: https://www.nucleodoconhecimento.com.br/здравоохранение/тяжелой- 
инфекционная и паразитарная плотность). А маленькие дети, первые инфицированные и беременные женщины - хозяева, которые более уязвимы к тяжелым формам болезни, как было сказано в ходе работы.

Таблица 3 - Распределение условий, указывающих на тяжесть и необходимость госпитализации в соответствии с инфицированными видами у пациентов, госпитализированных с тяжелой малярией в 2016 году, Macapá - AP.

\begin{tabular}{lccccccc}
\hline \multirow{2}{*}{\begin{tabular}{c} 
Condições que indicam gravidade $\begin{array}{c}\text { Espécie Infectante } \\
\text { necessidade de internação }\end{array}$ \\
\cline { 2 - 8 }
\end{tabular}} & $\begin{array}{c}\text { P. falciparun } \\
(\mathrm{N}=13)\end{array}$ & $\begin{array}{c}P . \text { Vivax } \\
(\mathrm{N}=34)\end{array}$ & \multicolumn{3}{c}{$\begin{array}{c}\text { Total } \\
(\mathrm{N}=47)\end{array}$} \\
\cline { 2 - 8 } & $\mathrm{N}$ & $\%$ & $\mathrm{~N}$ & $\%$ & $\mathrm{~N}$ & $\%$ \\
\hline Vômitos repetidos & 13 & 32 & 28 & 68 & 41 & 100 \\
Icterícia & 3 & 27 & 8 & 73 & 11 & 100 \\
Dispneia & 3 & 30 & 7 & 70 & 10 & 100 \\
Idade $<1$ ano & 0 & 0 & 10 & 100 & 10 & 100 \\
Anemia Intensa $(\mathrm{Hb}<5 \mathrm{~g} / \mathrm{dL})$ & 1 & 20 & 4 & 80 & 5 & 100 \\
Oligúria & 1 & 33 & 2 & 67 & 3 & 100 \\
Convulsão & 0 & 0 & 2 & 100 & 2 & 100 \\
Hemorragias & 0 & 0 & 1 & 100 & 1 & 100 \\
\hline
\end{tabular}

Самый высокий уровень паразитамии был зарегистрирован при $P$. falciparum с 192 000f/mm³. Среди изучаемых пациентов P. vivax показал максимальный уровень $30,000 \mathrm{v} / \mathrm{mm}^{3}$. Основные патогенные события приписываются $P$. falciprum хорошо описаны в литературе как способность инфицировать эритроциты на всех стадиях, тем самым представляя высокие паразитами, явление секвестра инфицированных эритроцитов из периферического кровообращения и способность к адектуму эндотелия капилляров внутренних органов, так что несколько зрелых форм наблюдаются в периферических образцах крови во время инфекции (KIRCHGATTER; PORTILLO, 2005; CARVALHO et al., 2010).

Что касается лабораторного профиля (Таблица 4), гематологические тесты показали, что у 91\% (43/47) пациентов эритроциты были ниже контрольных

$\mathrm{RC}: 87556$

Доступно в: https://www.nucleodoconhecimento.com.br/здравоохранение/тяжелой- 
значений, а в $100 \%$ случаев были низкие гемоглобин и гематокрит. $\mathrm{N}=34$ пациента имели тромбоцитопению (пониженное количество тромбоцитов), из них $71 \%(\mathrm{n}=24)$ имели малярию $P$. vivax и $29 \%(\mathrm{n}=10)$ P. falciparum. Эти гематологические свидетельства очень часты, особенно в случаях тяжелой малярии (RAMOS, 2006; LACERDA et al., 2012; SIROMA, 2016).

Таблица 4 - Распределение результатов лабораторных тестов пациентов, лечения тяжелой малярии в 2016 году, Macapá - AP.

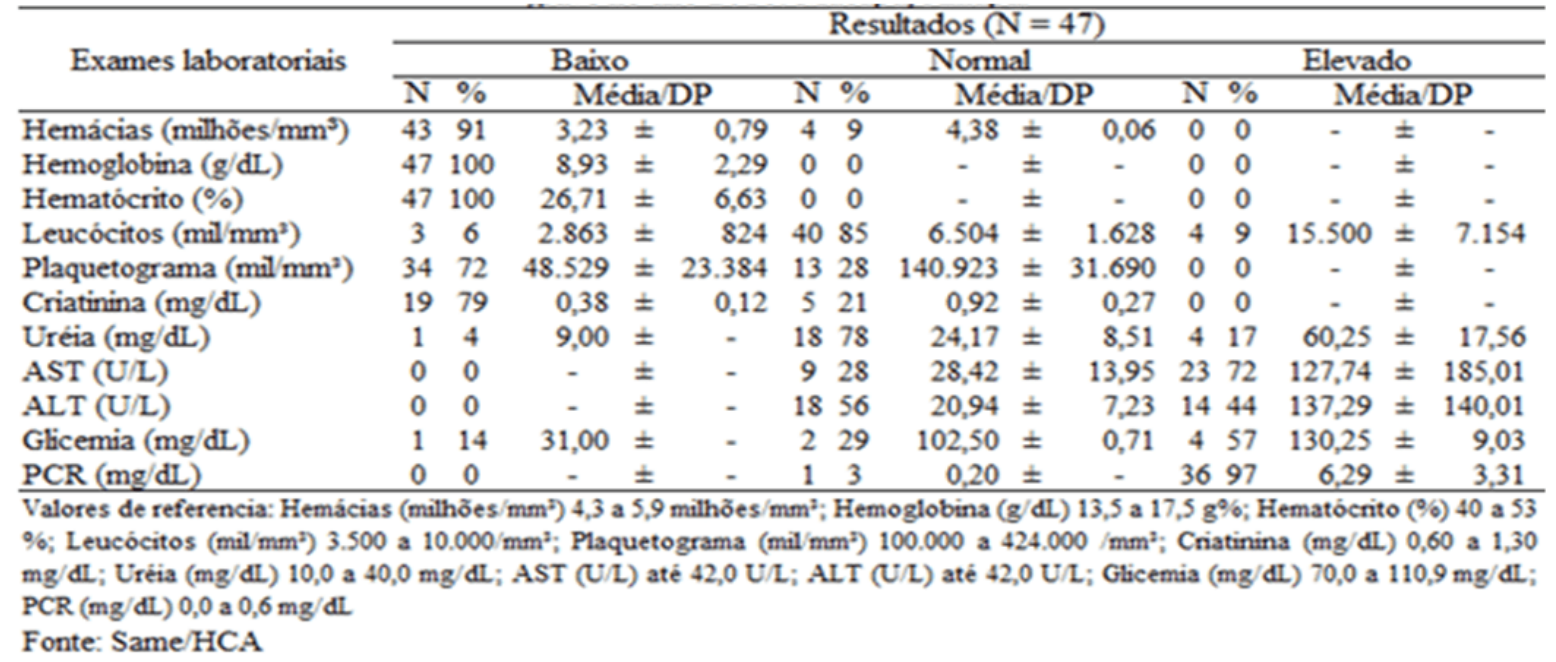

Что касается мочевины и креатинина дозы, которые оценивают функции почек, только мочевина выделяется с высокими значениями, которые могут указывать на почечную вовлеченность. Из (23/47) пациентов, которые прошли этот тест, только 17\% (n'4) имели высокие значения, все из которых были затронуты $P$. vivax.

С другой стороны, тесты, которые являются частью оценки печени, аспарта аминотрансферазы (АCT) и Аланина аминотрансфреразы (ALT) были выполнены в 68\% (32/47) пациентов, и из 32, они имели высокие значения (ACT) 72\% (n-23), среди которых 22\% (n'7) были P. falciparum и 50\% (n'16) были

RC: 87556

Доступно в: https://www.nucleodoconhecimento.com.br/здравоохранение/тяжелой- 
P.vivax. И 44\% (14/32) имели высокие результаты (ALT), и 19\% (n'6) были $P$. falciparum e $25 \%(n=8)$ eram $P$. vivax.

Высота трансаминазы (таблица 4), а также наличие желтухи (таблица 3) показывают печеночной нарушений, таких как бесполый цикл плазмодия называется доэритроцитов или ткани шизогонии, происходит в печени нарушение гепатоцитов, в конечном итоге приводит к воспалительному процессу в этом органе (RAMOS, 2006; BRASIL, 2009).

Что касается анализа глюкозы в крови, было обнаружено, что только 7/47 (15\%) были выполнены, где из этого общего числа (n'1) пострадавших om. P. Vivax, представлен гипогликемия, которая является обычным явлением при тяжелой малярии, как правило, происходит в связи с другими осложнениями (GOMES, 2011; RIBEIRO, 2012).

Отмечается, что 40/47 (85\%) пациентов не проходят гликемическое тестирование, в соответствии с практическим руководством по лечению малярии в Бразилии, гликемия является одним из лабораторных определений, а также анализ крови, определение паразитамии, артериального газа крови и почечной и печеной функции параметров (BRASIL, 2010). Отсутствие документации результатов анализов пациентов затрудняет наблюдать динамику заболевания, то есть отслеживать клинический профиль пациентов.

Измерение С-реактивного белка (CRP) было выполнено у 79\% (37/47) пациентов, из них ( $\mathrm{n}=37)$ 97\% ( $\mathrm{n}=36)$ имели высокие уровни С-реактивного белка. Пациенты с высокими уровнями составляли $24 \%(\mathrm{n}=9)$ P. falciparum и $73 \%(\mathrm{n}=27)$ P. vivax.

С-реактивный белок синтезируется в печени является неспецифическим маркером, который поднимается в острой фазовой реакции, когда повреждение тканей стимулирует, в том числе инфекции различных микроорганизмов

RC: 87556

Доступно в: https://www.nucleodoconhecimento.com.br/здравоохранение/тяжелой- 
(COLLARES, 2006). Уже выявлены данные о повышении уровня ВИ-реактивной белковой плазмы и прогрессировании тяжести малярии (LACERDA et al., 2012).

P. vivax и $P$. falciparum являются основными видами, вызывающими малярию человека, потому что они несут ответственность за большинство случаев заболеваемости и смертности в мире. В то время как. P. falciparum считается самым смертоносным видом, $P$. vivax считается наиболее широко распространенным на земном шаре (BATTLE et al., 2014).

\section{ВЫводы}

Это исследование показало эпидемиологический, клинический и лабораторный профиль тяжелой малярии у детей и подростков, принимая во внимание не только Plasmodium falciparum инфекций, которые обычно рекомендуется в качестве основной причины тяжелой малярии, но осложнения, связанные с Plasmodium vivax были тщательно описаны.

В настоящем исследовании можно было наблюдать как $P$. falciparum, так и $P$. vivax, связанные с тяжелой фрормой малярии. Была обнаружена высокая доля инфекции P. vivax, которая стала причиной единственного случая кровотечения, двух только приступов и восьми переливаний крови. Обнаружение многих госпитализаций по поводу инфекции $P$. vivax подчеркивает потенциальную опасность этого вида.

Однако необходимы дополнительные исследования для выяснения патофизиологических механизмов, приводящих к тяжелой форме малярии, вызванной P. vivax. Как только новый сценарий малярии покажет, что Plasmodium vivax изменил свой способ взаимодействия с человеческим хозяином, он больше не может считаться доброкачественным паразитом. Осуществление этого сдвига парадигмы еще больше усложняет борьбу с этим заболеванием, поскольку $P$. vivax считается наиболее распространенным

$\mathrm{RC}: 87556$

Доступно в: https://www.nucleodoconhecimento.com.br/здравоохранение/тяжелой- 
видом в мире, это может привести к ухудшению нынешней ситуации с малярией.

Несмотря на то, что настоящее исследование не переводит распространенность популяции Аmapá, представленные здесь данные могут способствовать повышению потребностей в уходе, способствовать улучшению адаптации специализированных услуг. Потому что выявление эпидемиологических, клинических и лабораторных данных о тяжелой малярии является стратегией ранней диагностики и надлежащего лечения, направленной на смягчение последствий, вызванных болезнью.

\section{ссылки}

ALMEIDA, H.K. S. et al. Casos confirmados de malária no Brasil entre os anos de 2011 e 2015. Revista Científica Multidisciplinar Núcleo do Conhecimento. Ano 05, Ed. 04, Vol. 07, pp. 05-16, 2020. ISSN: 2448-0959, Disponível em: <https://www.nucleodoconhecimento.com.br/saude/malaria-no-brasil>, $\quad$ DOI: 10.32749/nucleodoconhecimento.com.br/saude/malaria-no-brasil

BATTLE, K. E. et al. Geographical variation in Plasmodium vivax relapse. Malaria Journal, 2014, 13:144. https://doi.org/10.1186/1475-2875-13-144.

BOTELHO, C. et al. Manifestações respiratórias na malária por Plamodium falciparum e vivax. Rev. Inst. Med. trop. São Paulo, 1987 29(6):337-345.

BRASIL. Revista Pan-Amazônica de Saúde, v.4, n.2, p.33-43, 2013. Disponível em: <http://dx.doi.org/10.5123/S2176-62232013000200005

BRASIL. Ministério da Saúde. Guia prático de tratamento da malária no Brasil. Brasília: Ministério da Saúde, 2010.

$\mathrm{RC}: 87556$

Доступно в: https://www.nucleodoconhecimento.com.br/здравоохранение/тяжелой- 
BRASIL. Ministério da Saúde. Secretaria de Vigilância em Saúde. Plano de eliminação de malária no Brasil. Brasília: Ministério da Saúde, 2016.

BRASIL. Ministério da Saúde. Conselho Nacional de Saúde. Resolução № 466, de 12 de dezembro de 2012. Diretrizes e normas regulamentadoras de pesquisas envolvendo seres humanos. Diário Oficial da União, Brasília, DF, 13 jun. 2013. Seção I, p.59-62.

. Ministério da Saúde. Manual de diagnóstico laboratorial da malária. 2 ed. Brasília: Ministério da Saúde, 2009.

CARDOSO, Rosilene Ferreira. Efeito da sazonalidade na curva endêmica da malária por Plasmodium falciparum e vivax no garimpo do Lourenço: uma série temporal histórica na Zona da Amazônia Brasileira. UFRGS. 2014. Disponível em: http://hdl.handle.net/ 10183/114973. Acesso em: 06/11/2017.

CARVALHO, Bruna O. et al. On the Cytoadhesion of Plasmodium vivax-Infected Erythrocytes, The Journal of Infectious Diseases, Volume 202, Issue 4, 15 August 2010, Pages 638-647, https://doi.org/10.1086/654815. Acess: 12/09/2017.

COLLARES, Guilherme Birchal; PAULINO, Urquiza Helena Meira. Aplicações clínicas atuais da proteína c reativa. Rev Med Minas Gerais, 2006; 16(4): 227-333. Disponível em: http://rmmg.org/artigo/detalhes/579. Acesso em: 15/11/2017.

GOMES, Andréia Patricia. et al. Malária grave por Plasmodium falciparum. Rev Ter Intensiva. Viçosa (MG). v 23, n 358 - 369, 2011.

HADDAD, Nagib. Metodologia de estudos em ciências da saúde. São Paulo: Roca; 2004.

$\mathrm{RC}: 87556$

Доступно в: https://www.nucleodoconhecimento.com.br/здравоохранение/тяжелой- 
KIRCHGATTER, Karin; PORTILO, Hernando A. Del. Aspectos Clínicos e Moleculares da Malária Grave. Anais da Academia Brasileira de Ciências. Rio de Janeiro, v. 77, n 3, 2005.

LACERDA, M. V. et al. Understanding the clinical spectrum of complicated Plasmodium vivax malaria: a systematic review on the contributions of the Brazilian literature. Malaria Journal, 11, 12.2012.

LOPES, Stefanie C. P. et al. Paucity of Plasmodium vivaxMature Schizonts in Peripheral Blood Is Associated With Their Increased Cytoadhesive Potential, The Journal of Infectious Diseases, Volume 209, Issue 9, 1 May 2014, Pages 14031407, https://doi.org/10.1093/infdis/jiu018. Acess: 12/09/2017.

MACIEL, Giovana Belem Moreira Lima; OLIVEIRA, Elaine Cristina de. Perfil entomológico e epidemiológico da malária em região garimpeira no norte do Mato Grosso, 2011. Epidemiol. Serv. Saúde, Brasília, v. 23, n. 2, p. 355-360, jun. 2014.

MIOTO, Leide Daiana; GALHARDI, Ligia Carla Faccin; AMARANTE, Marla Karine. Aspectos parasitológicos e imunológicos da malária. Biosaúde, Londrina, v. 14, n. 1, 2012. Disponível: http://www.uel.br/revistas/uel/index.php/biosaude/article/view/ 24324/17894. Acesso em: 07/11/2017.

MONTEIRO, M. R. C. C.; RIBEIRO, M. C.; FERNANDES, S. C. Aspectos clínicos e epidemiológicos da malária em um hospital universitário de Belém, Estado do Pará,

NAING, Cho et al. "Is Plasmodium Vivax Malaria a Severe Malaria?: A Systematic Review and Meta-Analysis." PLoS Neglected Tropical Diseases 8.8 (2014): e3071. PMC. Web. 16 Nov. 2017. Doi: 10.1371/journal.pntd.0003071

PARISE, Éldi Vendrame. Malária grave em Palmas, Estado do Tocantins: relato de caso. Rev. Soc. Bras. Med. Trop. [online]. 2009, vol.42, n.4, pp.463-468. ISSN 0037-8682. http://dx.doi.org/10.1590/S0037-86822009000400021.

$\mathrm{RC}: 87556$

Доступно в: https://www.nucleodoconhecimento.com.br/здравоохранение/тяжелой- 
PRICE, R. N. et al. Vivax malaria: neglected and not benign. The American Journal of Tropical Medicine and Hygiene, Volume 77, Issue 6_Suppl, Dec 2007, p. 79 87. DOI: https://doi.org/10.4269/ajtmh.2007.77.79

RAMASAMY, Ranjan. Zoonotic malaria-global overview and research and policy needs. Frontiers in public health, v. 2, 2014.

RAMOS, Cristina Bastos Silva Raposo. Malária vivax na pré-amazônia maranhense: aspectos epidemiológicos e características clínicas. 2006. 110 f., il. Dissertação (Mestrado em Ciências Florestais)-Universidade de Brasília, Brasília, 2006.

SALAS, Briegel de Las et al. Adherence to human lung microvascular endothelial cells (HMVEC-L) of Plasmodium vivax isolates from Colombia. Malaria Journal. 2013,12: 347-10.1186/1475-2875-12-347. https://doi.org/10.1186/1475-2875-12-347. Access: 12/11/2017.

SANTOS, Rafael Cleison Silva dos; SANTOS, Elinaldo da Conceição dos. Malária: cobaias humanas no Amapá. Estação Científica (UNIFAP). Macapá, v. 1, n. 2, p. 143-150, 2011. Disponível em: https://periodicos.unifap.br/index.php/estacao/article/ download/244/cleisonv1n2.pdf. Acesso : 08/10/2016.

SIROMA, Thais Keiko; FERRARI, Eduardo Cal; RIGO, Rosângela Silva. Plasmodium vivax: causa de malária grave. Revista da Sociedade Brasileira de Clínica Médica. $2016 \quad$ jul-set;14(3):166-71. Disponível: http://www.sbcm.org.br/revistas/RBCM/RBCM-2016-03.pdf\#page=47

TA, Thuy $\mathrm{H}$. et al. First case of a naturally acquired human infection with Plasmodium cynomolgi. Malaria journal, v. 13, n. 1, p. 68, 2014.

VAL, Fernando et al. Are respiratory complications of Plasmodium vivax malaria na underestimated problem?. Malaria Journal, v. 16, n. 1, p. 495, 2017.

$\mathrm{RC}: 87556$

Доступно в: https://www.nucleodoconhecimento.com.br/здравоохранение/тяжелой- 
VENTURA, Ana Maria Revorêdo da Silva, Et al. Malária por Plasmodium vivax em crianças e adolescentes - aspectos epidemiológicos, clínicos e laboratoriais. J Pediatr 75: 187-194, 1999.

WASSMER, Samuel C. et al. "Investigating the Pathogenesis of Severe Malaria: A Multidisciplinary and Cross-Geographical Approach." The American Journal of Tropical Medicine and Hygiene 93.3 Suppl (2015): 42-56. PMC. http://doi.org/10.4269/ajtmh.14-0841 Web. 19 June 2017.

Представлено: Июнь 2020.

Утверждено: Июнь 2020 года.

RC: 87556

Доступно в: https://www.nucleodoconhecimento.com.br/здравоохранение/тяжелой- 